\title{
Research on the cultivation of Chinese competitive sports reserve talents based on the theory of Multiple Intelligences
}

\author{
ZHANG Fan \\ Department of Police Skills and Tactics, Nanjing Forest Police College \\ Sports Science postdoctoral programme, Nanjing Normal University \\ Nanjing 210023, China \\ zhangfan@nfpc.edu.cn
}

\begin{abstract}
In the training process of young athletes, sports schools often only pay attention to the training of "champion", neglecting the cultivation of "educating people". Although it plays an important role in the rise of Chinese competitive sports in a short time, the painful prices of this "gold medal" pursuit are more and more criticized. And many negative phenomena of it become increasingly prominent, such as athletes' moral accomplishment, professional accomplishment and social problems caused by lacking social survival ability. On the basis of the theory of multiple intelligences, from the humanistic quality, cultural learning, scientific training, social practice in 4 aspects of collaborative development as the starting point, in order to cultivate a high skill level, good moral quality, harmonious athletes physical and mental health, personality and comprehensive development as the ultimate aim. Construction of "four in one" competitive sports reserve personnel training system.
\end{abstract}

Keywords-multiple intelligence; competitive sports; reserve talents; young athlete; intelligence

\section{INTRODUCTION}

Currently, too much emphasis on the physical and psychological qualities as well as skills and tactics and the underestimation of cultivating other quality led to the powerlessness of young athletes in competitive sports and the poor comprehensive quality so that there even emerged some negative behaviors made by them in the society. The main reason of those phenomena lay in the absence of bringing the athletes' subjectivity into full play and the neglecting of cultivating their coordinated development of comprehensive quality. From historical experiences, we can conclude that, in the development of competitive sports, if we ignore the link of "educating people", people we train may be the imperfect "social man", and competitive sports will not make a qualitative leap. In order to implement the coordinated development of "educating people" and "winning", it is necessary to reexamine the current training of reserve talents in China's competitive sports.

\section{INTERNAL MECHANISM OF MULTIPLE INTELLIGENCES THEORY AND THE TRAINING OF RESERVE TALENTS}

The theory of Multiple Intelligences thinks that human intelligence includes at least eight kinds of intelligences [1]: linguistic intelligence, logical-mathematical intelligence, spatial intelligence, bodily-kinesthetic intelligence, musical intelligence, interpersonal intelligence, intrapersonal intelligence and natural exploration intelligence. The core point of this theory emphasizes that, in the process of talent training, we should be people-oriented and teach students in accordance with their aptitude; that is, we should take multiple education on the basis of respecting young athletes' differences, and fundamentally promote young athletes to understand the knowledge or skills they learn, and finally realize the goal of the collaborative development of superior intelligence and other intelligences. However, under the influence of the traditional concept of sports reserve talents cultivation, the so-called "excellent athletes" only have good sports intelligence, and it is not important for them to develop other intelligences coordinately. To become a good athletic talent, it is far from enough for them to have a proficient motor skill and a high level of exercise, as it is only one of the standards of becoming a "man" , not all. And this kind of concept is exactly consistent with the core point of the theory of Multiple Intelligences.

\section{CHINA'S RESERVE TALENTS TRAINING IS FACING A GRIM SITUATION UNDER THE NEW SITUATION}

\section{A. Contradiction between changing the development mode and the traditional training mode}

During a long time, the training of competitive sports reserve talents is still dominated by the "one-stop" and "single" mode. It not only causes the reserve talents training mode of "management of the whole nation system, profession of the amateur system ", but also causes that athletes' cultural learning and quality education have always been outside the education system, and they cannot 
enjoy the high-quality educational resources and the protection of the basic rights and interests of the people. In addition, the contradiction between the high risk and high elimination of competitive sports and the serious vacancy of career planning directly leads to it that the phenomenon of "the darling of the project and the changeling of the society" emerges in an endless stream. The current training model is the fundamental reason for the weakening of schools' running function and the reduction of its scale.

\section{B. Contradiction between satisfying social demands and the single specialty}

It is a basic, strategic and long-term systematic project to cultivate reserve talents in competitive sports, which not only needs to regard winning glory for the country as the highest form of expression, but also needs to maximize the value of the individual athlete. Therefore, we should attach the same importance to the positioning of the individual athlete's sports career as well as the planning and development of his social career. However, the current "single, closed and extensive" training mode is divorced from the track of social development, and does not understand the guideline of "people-oriented and comprehensive training" advocated by the state, which only focuses on the surface of the operation, without paying attention to the training process and the evaluation of social benefits. Especially in the process of running schools, the ideologies of "playing for medals" and "quick success " have not been fundamentally reversed and curbed. These are the contradictions and problems that need to be solved urgently.

\section{REFLECTION ON THE CULTIVATION OF RESERVE TALENTS BASED ON THE THEORY OF MULTIPLE INTELLIGENCES}

\section{A. Emphasis on "studying and educating", and the stress of "training and winning"}

The domestic scholars have reconciled the conflicting problems of "educating" and "winning", "studying" and "training" for many years, but the effect is not very significant. In fact, "educating" and "winning" should not be in conflict. Although there is an undeniable contradiction between the two, especially under the condition of limited resources, any complex society needs the training modes of both "educating" and "winning", according to the theory of Multiple Intelligences. In order to ensure the normal operation of the society, it needs "educating", and from the perspective of social contributions, it needs "winning". It means that people should adapt themselves to the society first, and then talk about their contributions. In other words, the competitive sports talent should first be the social man and then the athlete. As a result, in order to change the current predicament of China's sports talents cultivation, we should take the roads of "first man, then talent" and "first educating, then winning", which is the true value orientation of training qualified reserve talents.

\section{B. First "exercise intelligence", then "other intelligences"}

As far as the current situation of the competitive sports talents training is concerned, how to improve the quality of reserve talents through optimizing the training process is the core issue. And this kind of optimization should first achieve a balance among the development of the "man", the "society" and the "competitive sports". According to the theory of Multiple Intelligences [2,3], to train reserve talents who can adapt to the future development, it must regard meeting the needs of the society as the guide, promoting the people's development as the main line, and integrate knowledge-learning, ability-training and quality-improving into one to promote multiple development. Therefore, while strengthening the sports intelligence, it is necessary for cultivating allround athletic talents to promote the development of other intelligences, such as logical thinking, interpersonal relationship, selfcognition, etc. Of course, it does not mean to develop a "generalist" athlete, but to make a balance between "general knowledge" and "athletic talent"; that is, the athlete not only has excellent competitive performance, but also has the basic ability to adapt to the society.

\section{CONSTRUCTING A "FOUR IN ONE" TRAINING SYSTEM BASED ON THE THEORY OF MULTIPLE INTELLIGENCES}

For the reserve talents training in competitive sports, it is very important to plan and complete the training process scientifically. Combining the researches on the training of competitive sports schools at home and abroad and the theory of Multiple Intelligences, it is not difficult to analyze the main factors covered by the cultivation of competitive sports reserve talents (Table 1).

Table 1. The training system of "four in one" for reserve talents in competitive sports schools in China

\begin{tabular}{|l|l|l|}
\hline \multirow{2}{*}{ Classification standard } & \multicolumn{2}{|c|}{ Component and principle } \\
\cline { 2 - 3 } & \multicolumn{1}{|c|}{ Major component } & \multicolumn{1}{c|}{ Following principle } \\
\hline moral and aesthetics & humanistic quality & shaping a sound and perfect personality \\
\hline intellectual & cultural learning & adhere to the basic educational policy of our country \\
\hline physical & scientific training & abiding by the training rules of reserve talents in competitive sports \\
\hline labor & social practice & $\begin{array}{l}\text { complying with the direction of reform and development of China's } \\
\text { social and economic system }\end{array}$ \\
\hline
\end{tabular}




\section{A. Humanistic quality is the premise}

How to train a group of compound talents who have both competitive ability and humanistic quality, and can well adapt to the development law of competitive sports, is the inevitable requirement of the development of sports schools. Generally speaking, the structure of humanistic quality mainly includes philosophy, language, literature, history, morality, psychology, aesthetic level, etc. From the perspective of the realization of the athlete's own value, improving their humanistic quality is not only in accordance with the "educating and winning", but also helps promote the transformation and renewal of the reserve talents training ideas, and helps contribute to the implementation of the new model of reserve talents training, and is of great significance to comprehensively promote the combination of physical education and teaching. Specifically, since the reserve talents have the dual identities of both athletes and young athletes, the path of humanistic quality training can be understood from these two dimensions: 1) From the view of athletes, strengthening the training of humanistic quality is the breakthrough to promote the combination of physical education and teaching, and the foundation of forming the reserve talents' moral qualities, special sports qualities and physical and mental qualities. More importantly, it will help them enhance their overall competitive qualities. Only with profound cultural background, can we have a deeper understanding of the special sports we are engaged in. 2) From the point of students, the cultivation of humanistic quality can help them become the qualified "social man", which means to have rich cultural knowledge, the correct grasp of humanistic ideas, the flexible humanistic methods and the scientific humanistic spirit. Humanistic quality education of sports talents is an important way to improve their cultural accomplishment, aesthetic taste, competitive culture and sports level, an integral part of the overall training objectives and training models, and a kind of educational thought and concept [4]. Therefore, to establish the ideas of "first man, then talent" and "first educating, then winning", and the talents' training idea of equal attention to competitive sports and humanistic quality. And to take this as an opportunity to combine teaching the cultural knowledge, fostering the sports level and enhancing the comprehensive qualities, which is also an effective way to create talents with excellent qualities and competitive abilities in China.

\section{B. Cultural learning is the foundation stone}

If the humanistic quality is the premise of human development, the cultural knowledge is the foundation stone of human existence. For young athletes whose daily training tasks are relatively heavy, it is very important to use limited time to efficiently absorb the scientific and cultural knowledge in order to construct their own knowledge structure system. In the future, whether in the arena or in life, the degree of internalization of knowledge structure, as well as the ability to actively accept, absorb and apply knowledge structure, will lay the foundation for future success. If the competitive ability is the athlete's hard power, the cultural learning is the soft power. Today, with the rapid development of sports technology and the increasingly fierce competition, the soft power of culture is becoming more and more important. Strengthening cultural education of athletes is helpful to improve their cultural literacy and personal accomplishment comprehensively, to improve their moral and national spirit, to establish a correct outlook on life and values, and to develop good personality and psychological quality, and to ensure their stability on the playing field [5]. At present, it is necessary to change the situation of "one missing, two insufficient" in the training of reserve talents in sports schools: 1) changing the situation that talents training leads to the lack of multi-valued evaluation of young athletes because of performance-oriented; 2) changing the situation that the low target orientation of cultural teaching leads to the lack of thirst for knowledge among young athletes; 3 ) changing the situation that the inflexible forms of cultural education lead to the lack of developmental potential for young athletes.

\section{Scientific training is the key}

With the competition of modern competitive sports becoming more and more scientific and technological; the degree of modernization of scientific training is of great importance. Therefore, sports schools should be scientific training oriented, focus on improving the quality continue to explore the special training rules, use modern monitoring means, teaching methods and training methods actively to improve the level of scientific training system, and constantly promote the performance of competitive sports reserve talents cultivation. It should be pointed out that the use of scientific ideas, means and methods for selection and training is only one of the connotations of "scientific training". According to the theory of Multiple Intelligence, the real scientific training should be under the guidance of the concept of "people-oriented", and based on the respect for the differences of athletes, and comprehensively use scientific training means and methods for teaching the course. It means that, to actively implement the new training concept of "teach students in accordance with their aptitude" in "people-oriented", we must change the past training concept of only emphasizing the "physical training" in "emphasizing training and ignoring education", and promote the transformation in the cultivation of competitive sports talents from "material standard" to "human standard", and establish a new scientific training concept of the fusion of humanities and science [6]. In addition, sports schools also should pay attention to training the creative ability and independent thinking ability of athletes, because it is not only a comprehensive use of various knowledge to creatively solve the new problems in the competitive situation, no precedent to follow, especially the ability of solving difficult problems, but also a key factor to stimulate more training enthusiasm and positive attitude after fully understanding the exercise programs, which contributes a lot to the breakthrough in the special level of competition .

\section{Social practice is the guarantee}

In order to realize the sustainable development of competitive sports, sports schools must pay attention to the harmonious development of young athletes' individual body and mind in the process of reserve talents training. It requires objectively sports 
schools to carry out social practice according to the project characteristics and actual conditions of the talents, and to guide and help athletes to establish a scientific and reasonable life orientation and occupation planning, so that they can correctly understand and explore their potentials, enhance their competitive abilities, practical abilities and comprehensive qualities to adapt to their cruel future in competitive sports. As for the development target of reserve talents, one is to realize the occupational value of athletes themselves, contributing to the cause of competitive sports in China; the two is to lay a foundation for their occupational transformation, contributing to the overall cause of social development in China. In this sense, from the optimization point, sports schools should be on the basis of comprehensive consideration of sports talent, competitive level, special development level and other factors to train young athletes' abilities which are used for making accurate life orientation and career planning. During this process, if athletes' knowledge level, social experience, competitive ability do not satisfy the requirements of their life orientation and career planning, it is necessary to strengthen the training and guidance. In addition, sports schools must also carry out the education and guidance of mental health, and improve their psychological quality, in order to achieve the coordinated development of physical quality, psychological quality, cultural quality, and moral quality, becoming all-round people. Obviously, reasonable life orientation and occupational planning are beneficial for reserve talents to identify their own goals, know themselves better and make self-positioning. Besides, it is conductive to improving the level of self-management, and improving the overall qualities and development of reserve talents.

\section{SUMMARY}

The concept of the pluralistic development of man's intelligences, advocated by the theory of Multiple Intelligences, not only satisfies the requirements of the whole society for the development of competitive sports, but also meets the requirements of the society for all-round development of people. In the past, the problems exposed by the training mode of competitive sports reserve talents have been continuously challenged and criticized by the society. Sports schools must update those backward training ideas, and actively integrate the idea of multiple intelligences into the training process. In addition, sports schools should establish the training idea of "first man, then talent" , and practice the training mode of "four in one", making the reserve talents training more humane. Only in this way can sports schools adapt to the trend of the times, and promote the sustainable development of competitive sports in China.

\section{ACKNOWLEDGMENT}

This work was supported in part by the Project of the Fundamental Research Funds for the Central Universities under Grant LGZD201709, in part by the Project of China Postdoctoral Science Foundation under Grant 2017M611849, in part by Jiangsu Qing LAN Project under Grant 2017, and in part by Nanjing Forest police College Teaching Reform Project under Grant ZD17001 \& YB17001.

\section{REFERENCES}

[1] Gardner, H, The five Minds for the Future, School Administrator, vol. 5, pp. 262-263, January 2009.

[2] Andronache, D., Bocoş, M., Stanciu, D. I., Raluca, B.O, The valences of multiple intelligences theory in optimizing the training process, Educational Sciences, vol. 13, pp. 18-26, February 2011.

[3] Heidari, F., Khorasaniha, N, Delving into the Relationship between LOC, MI, and Reading Proficiency, Language Teaching \& Research, vol. 4, pp. 89-96, April 2011.

[4] SUN K.H., JI L., WANG K., Research on Structure of Young Athletes' Sportsmanship and Its Related Characteristics, China Sport Science, vol. 33, pp. 5661, March 2013. ( In Chinese)

[5] ZHU K., ZHAO B.J., WANG X., On Hot Topics Research and Its Evolution Route of Reserved Sports Talents Training in China, Journal of Shanghai Physical Education Institute, vol. 21, pp. 62-74, July 2011. (In Chinese)

[6] ZHAO M.J., WU X., Enlightenment from American Youth Sports and Athletic Talent development, Sports \& Science, vol. 35, pp. 51-54, June 2014. ( In Chinese) 